\title{
CONSIDERATIONS REGARDING THE POSSIBILITY OF IMPLEMENTING A MODEL FOR THE EVALUATION OF THE LEVEL OF CADETS' PHYSICAL TRAINING
}

\author{
Robert STĂNCIULESCU \\ "Nicolae Bălcescu" Land Forces Academy, Sibiu, Romania \\ rstanciulescu@armyacademy.ro \\ Cristian STĂNCIULESCU \\ The General Inspectorate of the Romanian Police, Sibiu, Romania \\ stanciulescu.robert60@gmail.com
}

\begin{abstract}
The analysis of military conflicts in the latter part of the twentieth century has led to a revision of ideas about the concept of physical training in modern armies in Europe and America. The dimensions of the scientific and technical revolution show that the power of military imposition depends on the intensive technologies of knowledge, and physical training has been redefined as an urgent need in the training of the military and placed in its proper place. Not only is it no longer neglected, but, as if more than ever, from the data provided by foreign military literature, it is clear that the training of the fighter begins and ends with physical exercises. Military specialists say that in increasing combat capability, physical condition comes immediately after the technical and tactical experience in terms of importance, representing 20-30\% of the time allocated to training for combat. This orientation includes the theory of the training practice of future students in the Land Forces Academy, the assessment of the level of physical training being an essential objective in the training system.
\end{abstract}

KEYWORDS: war, combatants, fighter, evaluation, potential, model

\section{Introduction}

The experience of military conflicts in history, and in recent times as well, shows that a competitive army must maintain a high degree of physical training and mental endurance of fighters (Stănciulescu, 2016).

Military commanders and theorists recognize the importance of physical training in achieving success by looking for specific methods and means to improve its level. Only the physically and mentally trained, multilateral and specialized soldier is able to perform his tasks accurately, with speed and quality, without unnecessary emotions and with minimal losses. The technical-scientific process that has contributed and substantially contributes to the creation of new types of weapons must not reduce the importance given to the physical training of the military and the time allocated to ensure adequate psychophysical potential for the increasingly more complex requirements of the modern battlefield.

History has refuted and continues to disprove such misconceptions, demonstrating that military technique, no matter how 
successful it is, cannot replace well-trained soldiers, and the high-performance means of combat are used in vain if fighters lack the morale and mentality of a conqueror due to deficient physical and mental training.

The level of physical training of a soldier has a great impact on his fighting ability, which very much depends on the training and assessment system used. The ability to withstand physical and mental stress in any climate, season and state of the weather, to the prolonged efforts required by combat is an important objective of the training system. Defining combat capability essentially means evaluating the instruction seen as a broad and complex process that proves the leadership ability, the degree of adequacy and functionality of the organizational structure, the level and consistency of staff training. Technical progress is beneficial to raising combat capability, but it depends to a large extent on the proper training of personnel, at least in terms of the performance of weapons and equipment. Nor is the state of operability given only by the means provided but in direct proportion to the proper training of the military. In these conditions, it is very clear that training in conditions as close as possible to reality is the common denominator of all the other factors on which the combat ability depends.

The whole process of training the military students aims to optimize professional training, which includes physical training among its basic elements. Obtaining a high level of physical training is achieved through intense training, corresponding to the specific objectives of physical training, led by specialists, with adequate specialized equipment, which ensures a high grade of progress.

Tests to check the level of physical training consist in assessing the most important physical qualities: cardiorespiratory endurance (the efficiency with which the body sends oxygen and substances necessary for muscle activity by eliminating the products that are no longer needed) and muscle strength, but at the same time the other motor qualities are not neglected, speed and dexterity respectively, with their forms of manifestation that substantially contribute to the formation, development and improvement of the basic and applicative motor skills and abilities. For the verification of these qualities, endurance exercises (runnings on variable distances $2-5 \mathrm{~km}$ ) and segmentary strength exercises (push-ups, abdominal flexions, tractions, etc.) are usually used.

These evaluations are extremely important for determining the effectiveness of the training systems to ensure that training is focused on the fulfillment of specific missions and to make regular estimates of the program achieved. Physical training also develops a large number of moral traits and acquisitions: self-control, discipline, camaraderie, self-knowledge, courage and perseverance.

Physical education teaches us to master the body and spirit, and systematic physical training strengthens muscles, increases joint elasticity, improves reflexes and ensures physical and moral balance. The effect of physical exercises is manifested by the possibility that the military acquires to act spontaneously and in a relaxed manner. Physical training does not aim at learning a simplistic method of fighting, but at developing a sense of the ability to intuitively synchronize one's actions in each situation so that the action becomes identical with the mission to be accomplished.

The profession of arms, like any other recognized profession, is distinguished by a continuous education necessary to maintain the vitality of the military system. It is perhaps the only profession that includes considerable risks, but risks assumed to obtain a noble desidertum, the defense of the homeland and of the national interest. The impact of the reform in the army is particularly strong and significant, the 
reform being a condition for achieving conceptual and action compatibility and interoperability with the armies of NATO member states. Thus, a series of mutations, transformations and changes take place in the field of training.

The promotion of the North Atlantic dimension of higher military education is determined by the continuation of the reform in the Romanian army, in order to achieve a modern body that meets all the standards imposed by NATO, with highly mobile structures, interoperable with allied countries, compatible with them, able to fulfill any kind of missions, wherever it will be needed within the Alliance to ensure Romania's security.

Prolonged physical exertion caused by the diversity and scale of combat actions, by extremely unfavorable conditions of climate, relief, and the wear and tear actions carried out by the enemy can paralyze the combat capability of physically unprepared troops. Therefore, physical training is achieved and improved primarily through the process of physical training, the training programs being aimed at improving the general physical condition (strength, endurance, speed), as well as the other abilities (coordination and intermediary), bearing in mind:

- the physical demands to be correlated with the situation that will follow;

- the exercises to be performed with all the equipment and with additional weights after mastering the techniques created for wearing and handling;

- the training in the field and running with combat weapons to be carried out in conditions adapted to the mission and the terrain and climate to be as harsh as possible;

- the survival in the field to be done in conditions of rapid change of demands and situations;

- the trainings take place in competitive form (development of the spirit of competition and self-overcoming) (Frunzeti et al., 2014).

\section{Place and Importance of Physical Training in the Process of Officers' Development}

As a component part of military physical education in particular, and of combat capability in general, the notion of physical training includes in itself a complex of physical and motor dispositions, optimally developed and functionally combined. Its level is determined by the capacity of the basic functional systems (nervous, cardiac, circulatory, emotional, etc.) and by the ability to mobilize these systems in stressful situations. Next, it is based on the general and special level of physical performance, on motor skills (the side related to condition) and special motor skills (the technical side).

Physical training is achieved and perfected primarily in the process of physical training, which is influenced in form and content by the direct action in the specialized military training and psychological forms. Prolonged physical exertion caused by the diversity and scale of combat actions, by extremely unfavorable conditions of climate, relief, by the wear and tear actions carried out by the enemy can paralyze the combat capability of any well-trained troops. Unexpected effects can create particularly serious conditions in the capacity for analysis and synthesis of decision-makers, with devastating consequences on the combat capability of troops.

It can be appreciated that physical training is of paramount importance today and as such it is considered a vital part of the combat training of the commander, in the first place and then of the other combatants. Through the means and methods available, physical training strengthens the human body, thinking and spirit and helps to reduce the consequences of the negative effects of the battlefield.

These coordinates can be achieved through intense training in which the efforts are not spared, using training methods and means by which the type of fighter required 
by the modern battlefield is moulded and obtained. Physical training programs are aimed at improving the general physical condition and developing the ability to withstand stress, substantially contributing to increased productivity, mental alertness, promoting cohesion and survival of the combat capability. In the Land Forces Academy the physical training program aims to develop and strengthen the students' motor skills in order to increase their physical and mental potential while maintaining their optimal physical and mental health. It aims to improve the anatomical structure and improve human body functions to achieve the best physical and mental performance.

As a totality of the means that ensure the physical development, an excellent state of health and special performances, it represents a process that takes place throughout the year and lasts throughout the military life, being at the same time a process of training, development and increase of the body's functional possibilities. It must be seen primarily as a process of adapting the body to the increasing functional efforts, to the ever new experiences, in terms of strength and speed, endurance and suppleness, coordination of movements and dexterity, mental strain and many other requirements.

\subsection{The System of Evaluation of the Cadets' Physical Training in the Land Forces Academy}

In the military physical education and sports system, the evaluation aims to provide information on the efficiency of the methodology, content and means of training, in the direction of achieving the proposed objectives, as well as in order to make possible decisions to lead to efficiency. It appears as a tool for measuring and assessing the quality of the physical education process and aims to determine whether the system fulfills its functions or not, i.e. whether it achieves its objectives. Evaluation is a necessary and mandatory act in the management of the educational process, which has precise objectives and which takes place under value control. Through evaluation we have the opportunity to know the level of motor qualities indices, the complexity and variety of the system of skills, the manner of manifestation of students, as well as the efficiency of the means of action used.

The evaluation of the level of physical training is performed within the tests and the differentiated standards established for each year of study, depending on the subject matters included in the established programs of study and objectives. Throughout the training process, the evaluation is performed at the following events:

- speed running $50 \mathrm{~m}$ flat;

- speed running $100 \mathrm{~m}$ flat;

- long jump from the spot;

- endurance running $2000 \mathrm{~m}$ flat;

- endurance running $3000 \mathrm{~m}$ flat;

- traction at a fixed bar in the strength of the arms;

- push ups on the ground;

- abdominal flexions;

- climbing on the rope (5 m);

- obstacle course for infantry Ex. 1;

- obstacle course for infantry Ex. 2;

- fast movement $(2 \mathrm{~km}, 3 \mathrm{~km}, 4 \mathrm{~km}$, $6 \mathrm{~km})$;

- throwing grenades at a distance and with precision;

- NATO type obstacle course.

\subsection{Theoretical Model of Evaluation of Physical Training Level}

Identifying the professional model of the future officer is the first step in ensuring highly qualified human resources, able to effectively manage military action. Constituted as a set of general and specific competencies, abilities and capabilities, this model requires that the training of military students be adequate to the increased demands of the modern battlefield and the 
requirements of other missions that the land forces officer must perform.

The new demands of the modern battlefield raise the following physical and mental requirements for the fighters:

- to be a dynamic individual, resistant to prolonged physical effort on any type of terrain and weather;

- to have the ability to permanently adapt both physically and mentally to the complex changes that have occurred in the modern battlefield;

- to be able to develop, through sustained training, rapid reaction capabilities, simultaneously to several external stimuli;

- to be resilient by voluntarily accepting the full range of efforts;

- to have well-adapted basic motor skills (speed, strength, endurance) and to show skill and mobility in performing specific actions;

- to demonstrate skills of rapid orientation in the field, flexibility of visual and auditory attention;

- to have well-developed conditioned reflexes (Stănciulescu, 2017).

All this requires a high-quality human potential, resistant to the physical, climatic, seasonal and weather demands, to the prolonged efforts required by combat. We understand that the professional model of the officer necessarily includes constitutive and descriptive elements of a subcomponent regarding the physical potential of the officer within the competence of a fighter.

The physiognomy of the fighter, normally developed from the physical point of view is as follows: robust, perfectly healthy; resistant to weather conditions, perfectly integrated in the conditions of the action area; strong and resistant to the physical and mental demands to be fulfilled, valid also for the modern officer, it requires the realization of a mathematical model for evaluating the level of physical training that should include the coordinates described above.

The model must be based on the level of development of three basic motor qualities: speed, strength and endurance, their forms of manifestation, as well as on some basic motor skills and applied utilitarian skills. It aims to reach an equilibrium among the three basic motor qualities in reaching the level of general physical training, but also to assign different shares to the assessment events within the specific motor quality. Schematically, this theoretical model for assessing the level of physical training could look like this:

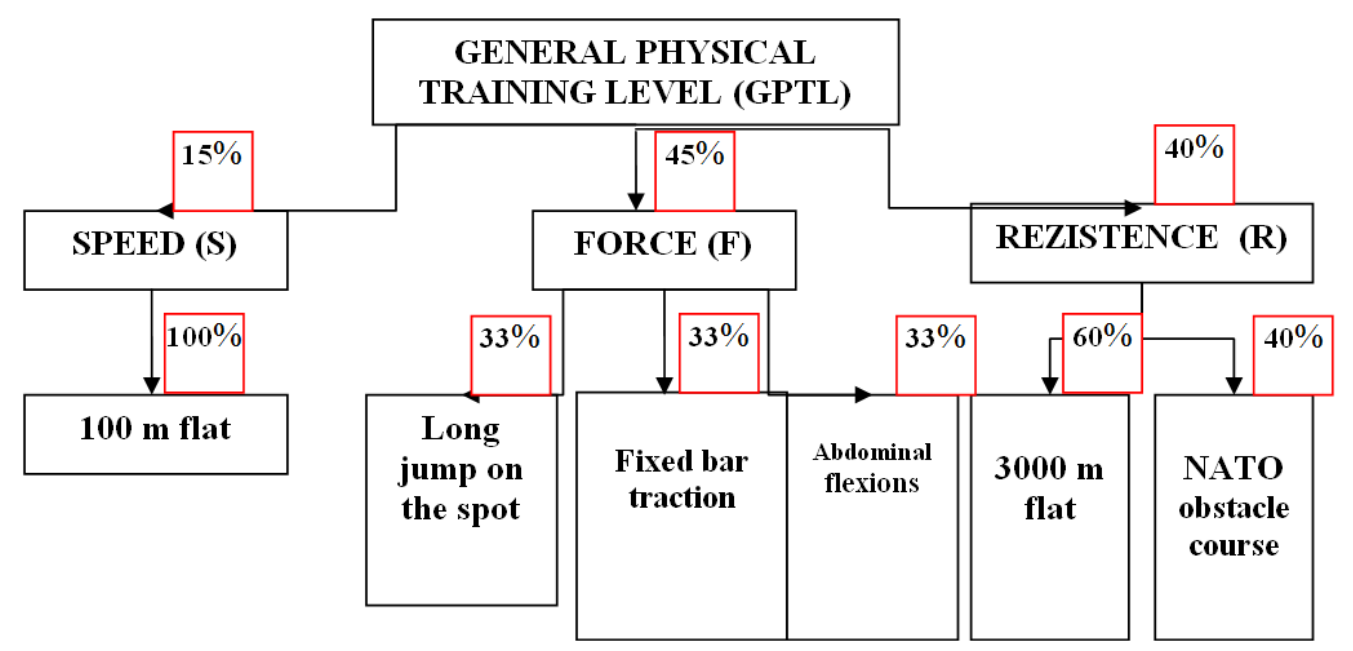

Figure no. 1: Model of evaluation of the general physical training level

(Source: Stănciulescu, 2017) 
Based on the model, the level of physical training will be calculated with the relation: $N P F G=15 \% \cdot V+45 \% \cdot\left(33 \% \cdot S_{L}+33 \% \cdot T_{B}+33 \% \cdot F_{A}\right)+40 \% \cdot\left(60 \% \cdot R_{P}+40 \% \cdot P\right)$

The calculation relationship highlights the share of elements that contribute to achieving an optimal level of general physical training for the students of the Land Forces Academy.

The model will be used in the analysis of a pilot experiment regarding the evaluation of the physical training level of the Land Forces Academy cadets, which can be validated/invalidated depending on the results obtained.

\section{Conclusions}

The teaching activity in military higher education must have the capacity to quickly adapt and without dysfunctions to the new training requirements of the army personnel that will be engaged in various military and non-military actions in the country and abroad. It is thus necessary that interoperability be achieved by implementing in the training contents the procedural and standardization doctrinal elements specific to all military institutions in the North Atlantic Alliance.
Given the resulting conclusions, the diversity and complexity of motor actions specific to identifying the level of physical training, as well as its optimization, I think that this evaluation method aimed at a proportional structure of the share of motor skills required in the military training activities is welcome and represents a step in the direction of identifying an efficient and realistic evaluation. We believe that, under these conditions, the model can greatly contribute to optimizing the level of physical training of future officers and can be an important objective of the issue addressed. In conclusion, it is imperative that the impact of the battlefield on the physical capacity of combatants should be taken into account, in order to identify the levers of action on the body of the fighter according to the concrete requirements of the extremely complex and demanding missions of the modern warfare.

\section{REFERENCES}

Frunzeti, T. et al. (2004). Concepţia soldatului mileniului III. București.

Stănciulescu, R. (2016). Capacitatea motrică. Fundamente teoretice și metodice. Sibiu: Editura Academiei Forțelor Terestre "Nicolae Bălcescu".

Stănciulescu, R. (2017). Didactica activităților fizice cu caracter aplicativ-militar. Sibiu: Editura Academiei Forțelor Terestre "Nicolae Bălcescu".

Tudor, V. (1998). Problematica evaluării în educaţia fizică şcolară. Aspecte fundamentale şi criterii de evaluare. Doctoral thesis, Bucureşti.

Tudor, V. (2001). Evaluarea în educaţia fizică şcolară. București: Printech. 